\title{
Intestinal Parasites in Dogs and Humans, Environmental Egg Contamination and Risk of Human Infection with Zoonotic Helminth Parasites from Dog in Hosanna Town
}

\author{
Yimer Mulugeta ${ }^{1}$,, Moti Yohannes ${ }^{2}$, Deneke Wolde ${ }^{3}$, Mesfin Aklilu ${ }^{1}$, Baye Ashenefe ${ }^{1}$, \\ Daselgn Gebree $^{1}$, Fantu Lombamo ${ }^{4}$, Gutu Kitila ${ }^{1}$, Garoma Getahun ${ }^{1}$, Asefa Deressa ${ }^{1}$, Hail Degefu ${ }^{2}$ \\ ${ }^{1}$ Directorate of Bacterial, Parasitic \& Zoonotic Diseases Research, Ethiopian Public Health Institute, Addis Ababa, Ethiopia \\ ${ }^{2}$ College of Agriculture \& School of Veterinary Medicine, Jimma University, Jimma, Ethiopia \\ ${ }^{3}$ College of Medicine \& Health Science, Wachemo University, Hosanna, Ethiopia \\ ${ }^{4}$ Department of Public Health, St. Paul's Hospital Millennium Medical College, Addis Ababa, Ethiopia
}

Email address:

dyime.mu9@gmail.com (Y. Mulugeta)

${ }^{*}$ Corresponding author

\section{To cite this article:}

Yimer Mulugeta, Moti Yohannes, Deneke Wolde, Mesfin Aklilu, Baye Ashenefe, Daselgn Getahun, Fantu Lombamo, Gutu Kitila, Garoma Getahun, Asefa Deressa, Hail Degefu. Intestinal Parasites in Dogs and Humans, Environmental Egg Contamination and Risk of Human Infection with Zoonotic Helminth Parasites from Dog in Hosanna Town. International Journal of Biomedical Materials Research. Vol. 7, No. 1, 2019, pp. 24-36. doi: 10.11648/j.ijbmr.20190701.14

Received: February 12, 2019; Accepted: March 14, 2019; Published: April 13, 2019

\begin{abstract}
Pets especially dogs are the most common and first domesticated companion animals throughout the world including Ethiopia. In developing countries the health status of the pets are neglected. However, potential hazards are associated with pet ownership; thus, the objectives of the study were to determine the prevalence of important zoonotic gastrointestinal helminthes infection in dogs and their owners as well as risk of environmental egg contamination and major associated factors in Hosanna, Ethiopia. Cross sectional study designs were employed (feces \& stool sample from dogs and dog owners, soil samples and questionnaires data were collected) \& statistical analysis were done using SPSS version 16 software. Based on coproscopy examination results; the overall prevalence of helminth infection in dogs were $71.6 \%$ $(\mathrm{n}=187 / 261)$. Species of parasites identified were: Ancylostoma caninum (49\%) followed by Toxocara canis (34\%), Toxocara leonine (7.2\%), Taenia species (4.2\%), Strongyloides stercoralis $(2.6 \%)$ and Trichuris vulpis $(1.9 \%)$. Prevalence of intestinal helminth among human were found 17.62\% (95\% CI: 13.20-22.79). Hookworm species (6.5\%) followed by Ascaris (4.6\%), H. nana $(2.7 \%)$, S. stercoralis (1.5\%), Taenia species $(1.5 \%)$ and $H$. diminatus $(0.8 \%)$ were identified in humans. The environmental egg contamination status were observed in five sites with helminthes egg. Trichuris, T. canis, Ancylostoma, A. lumbricoides, $S$. stercoralis and Taenia species eggs were the identified ones. The major risk factors for the spread and zoonotic transmissions of parasites were lack of treatment for dog (prevalence: $81.2 \%$, P value: 0.000 and $\mathrm{OR}(95 \% \mathrm{CI}), 6$ (7.1$35)$ ) and poor awareness on transmissible helminth intestinal parasites of dog (prevalence: $76.5 \% \mathrm{P}$ value: 0.002 and OR $(95 \% \mathrm{CI}): 2.5(1.36-4.4))$. In conclusion, this study revealed that the overall prevalence of intestinal helminthes were abundant among dogs, humans and soil sample. Therefore, de-worming of dog, community awareness creation, one-health approached surveillance strategies and further researches should be conducted.
\end{abstract}

Keywords: Dogs, Helminth, Hosanna, Human, Prevalence, Zoonoses

\section{Introduction}

Pets are companion animals that people take care of and that give them company, for pleasure rather than for utility. Dogs are known to have been kept as first pets and first domesticated species since prehistoric times and cats since the 16 century BC. Other common pets include birds, rabbits, rodents, raccoons, reptiles, amphibians, and even insects. Globally, 
more than $50 \%$ of all households keep one or more animals as pets. Dogs and cats are the most common pets [1-2].

Pets play key role in societies throughout the world. They are important companions in many households, contributing to the physical, social and emotional development of children and the well-being of their owners, especially the elderly [3]. The major roles include for entertainment, as racing and fighting, for hunting, as guards, draught animals, for food, or for commercial purposes, for transportation and for research. This all are attributed with proper management and proper healthcare status of pets. However, pets specifically dogs and cats also act as reservoirs of a large number of pathogens of parasitic zoonoses, such as toxoplasmosis [4], giardiasis [5], toxocariasis [6] and ancylostomiasis [7]. Their roles in transmitting human infections have been recognized worldwide [8-9].

In many African countries including Ethiopia, appropriate policies regarding pet ownership has never been exercised and awareness of owners regarding their effects on individual and community health remained poor. According to some studies, the prevalence of parasites with public health importance in household pets was found usually high [1011]; resulting in risk of zoonotic transmission from household pets to humans that may occur directly or indirectly via environmental factors. In that sense, different studies have demonstrated that the soil contamination of gardens and public grounds by infectious parasitic forms constitutes a significant zoonotic risk [12]. The risk is further increased by non-favorable ecological, human behavioral factors and low awareness of pet owners about the diseases they may acquire from their own pets [10, 13-14].

Most pet owners do not have enough awareness and understanding that their pets may carry worms capable of infecting people. Therefore, practicing veterinarians can provide an important public service by recommending regular fecal examinations, providing well-timed anthelmintic treatments, counseling clients on potential public health hazards, and advising them on any precautionary measures that may be taken. Veterinarians are in an ideal position to provide pet owners with this service because of their access to the pet-owning public, their knowledge and training, and their role in the human-animal bond [15].

In Ethiopia, veterinary researches mainly focus on large animals with no or little attention to pets like dogs and cats. Few studies that have been done so far are at the expense of research interests of limited veterinarians such as [16] in Nekemt; [17], in Debreziet [14], in Ambo and [18] in Wondogenet areas; which are small administrative units in a given town, of Ethiopia. In this regard, so far there is no available data on the occurrence of zoonotic helminth parasite/egg from dog and environment in Hosanna area, South Ethiopia. Therefore, the objectives of this research project were:

I. To determine the prevalence of gastro intestinal helminth infection in dogs and their owners in Hosanna, with special attention to potential zoonotic parasites.

II. To assess the contamination of the environment with zoonotic dog helminth eggs.

III. To assess the knowledge, attitude and the practice of dog owners on zoonotic dog parasites in the study area, Hosanna town, South Ethiopia.

\section{Materials and Methods}

\subsection{Description of the Study Area}

The study was conducted in Hosanna town, Southern, Ethiopia. Hosanna is located at $232 \mathrm{Km}$ away from Addis Ababa, Ethiopia [19-20]. Geographical location and other details of the study area are summarized under Figure 1.

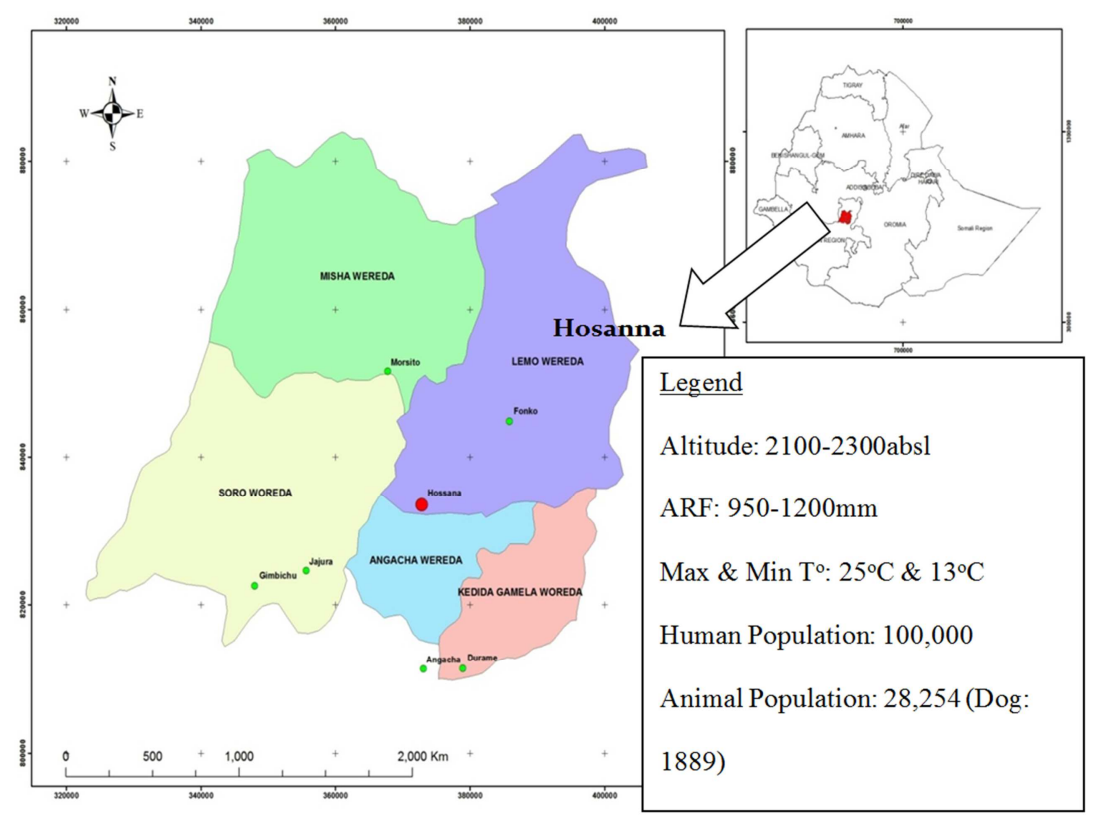

Figure 1. Geographical location of the study area. 


\subsection{Study Population}

The sampling units were all local and exotic breeds of household dogs of both sex and all age groups (young and adult) from Hosanna town.

The study populations used to study helminth parasite in human were all young children below 15 years old age living in the resident having dog, due to their high close contacting property with dogs and contaminated soil and also their low immune resistance of both sexes [21-22].

The study populations for the questionnaire survey were dog owners of different localities within Hosanna town, having different age, sex and educational background.

Soil samples were purposively collected from the different children plays ground, abattoir for beef animal slaughter and market areas (due to adjacent to abattoir and children also play over there) in Hosanna town, was selected as relatively high dog and people population coexist.

\subsection{Study Design}

Cross-sectional studies were carried out to determine the prevalence of gastro intestinal helminths parasites in human and dogs using parasitological technique including the risk of environmental egg contamination status.

A questionnaire survey was also applied to assess the risk factors associated with helminth infection in human and dog. Both open-ended and closed type questionnaires were applied to interview individual household head or in groups. The questionnaires were pre-tested in the field before administrating to the study population.

\subsection{Sample Size Determination and Sampling Methods}

\subsubsection{Sample Size Determination}

Dog

Sample size for faecal examination from dogs was determined by using sample size determination formula [23]. This formula indicated as: $\mathrm{N}=(1.96)^{2} \times \mathrm{PQ} / \mathrm{D}^{2} \approx 129 \approx 129$ $* 2 \approx 258$; Where $\mathrm{N}$ is the required sample size, $\mathrm{P}$ is expected prevalence $=(90.7 \%)$ by Jones et al in Wondo Gent, Southern Ethiopia through coprological study, Q is 1-P, D is the level of precision (5\%) and 1.96 is to indicate $95 \%$ confidence level [18]. Actually, the sample size is doubled to obtain 258 for the purpose of increasing the precision of the study. By adding $5 \%$ for non-response, a total of 270 subjects were included. However, $10(3.7 \%)$ subjects were excluded because of incomplete data a total of 261 subjects were enrolled in the study.

\section{Human}

Sample size for human stool examination was determined by using previous similar study expected prevalence (82.4\%) by Alemu et al in Zarima town, Northwest Ethiopia [24]. By using the same sample size determination formula like the dog above, were given us 223 individuals. Similarly, by adding $20 \%$ for non-response, a total of 267 individuals were included. However, $6(2.24 \%)$ subjects were excluded because of incomplete data or inabilities to provide stool sample a total of 261 individuals were enrolled in the study.

Using the same formula like the dog and fitting expected prevalence of $50 \%$ (no previous done study), which were given us 384 individuals for questioner interview of head of household who own dogs and if head not present other family member were selected.

Soil sample

Soil samples were collected purposively from an area of children plays ground or any area with high dog and people contact. Then by considering these, in Hosanna town seven areas were commonly known, that includes a single abattoir not fenced well and easily accessed by a number of dogs, a market area (for animals sale or purchase in a week once and the rest days occupied by dogs, due to being adjacent to abattoir to feed on offal's of animal slaughtered and also it is area for children plays), three separate common children play grounds in different position with respect to dogs existence and finally from Gofermeda area due to small /minor market and plane marshal public area and continuously visited by dogs.

\subsubsection{Sampling Methods}

For the purpose of this particular cross sectional study, households which owned dogs in the Hosanna town were first identified as a sampling frame then a systematic random sampling was employed to select a household. According to information from Hosanna town agricultural office, a total of 1889 dog population are owned by 1536 households. To identify households for collection of questioner data and stool sample from human and dog, randomly every fourth household was selected to get sample size calculated. In each selected household a single faecal sample from dog and household family member were collected for laboratory examination. In addition, questioner prepared for the study were administered to all household heads or others family members in the absence of the house head.

Soil samples were collected purposively from the different children playground, abattoir and market areas in Hosanna town.

\subsection{Parasitological Procedures}

Collection and examination of dog and dog owner's faecal/stool samples

Fresh fecal samples were collected from 261 house hold dogs and owners by systematic random sampling methods as described above in sampling methods. The fecal samples were collected at a specimen collection tubes in the morning time, and before collection the tube were labeled to identify one another and $10 \%$ formalin were added to preserve until processing [18]. Then faecal samples were submitted or transported from households to Hosanna collage of health science, medical laboratory for preparation and evaluation. The faecal samples were assessed visually to check presence of proglitids to categorize the sampled animal as Taenia species positive or negative then after samples were stored 
until conducting parasitological techniques. The sedimentation and floatation technique [25-26] were used to detect the presence of stomach and intestinal parastic eggs (cestodes and nematodes) in the samples. Helminth parasitic eggs load of each faecal sample were examined by the standard McMaster technique. After preparation immediately each faecal sample/slides was examined microscopically for parasite egg identification by using $10 \times 10$ magnification of light microscope. All helminth eggs were identified based on their morphological characteristic [27-28].

Collection and Examination of Soil Samples

Soil samples were collected purposively from an area of relatively high populations of dogs and childrens coexist. Down to a depth of not more than $3 \mathrm{~cm}$ by $10 \mathrm{~cm}$ surface, with each sample weighing an average of $200 \mathrm{~g}$ from an area of suspected risk area like abattoir area, market area, children play grounds as described by [29]. To represent that place/plot/area the samples were collected from corners and centers of total area ( 5 sites) with various distances between sampled sites as per the wideness of the area. Then collected soil samples were dried at room temperature and filtered through a set of two sieves with pore widths of 4 and $1 \mathrm{~mm}$ [30]. Afterwards, a 5-10 g sample was analyzed using coprological methods. Finally, the ova/larvae of helminth parasites were identified with reference to atlas of parasitology or their structures [27-28].

\subsection{Questionnaire Survey}

Structured questionnaires were designed to assess the knowledge, attitude and the practice of dog owners regarding on animal to human disease transmission (Zoonoses) from dogs in Hosanna town. The designed questionnaire were helped to gather information on the dogs', dog ownership, the occupation of the dog's owner, purpose of keeping dog, feeding of dogs, treatment for dogs, the extent of awareness on dog parasites, history of de-worming, control measures taken and other related factors. In this, individual interviews of the household heads or some other family member in the absence of the household heads were used.

\subsection{Data Analysis}

Collected data entered into Excel sheets and analysis was done by statistical package for social science (SPSS version 16.0). Descriptive statistics and logistic regression were used to analyze the risk factors and its association with helminthes parasitism. Associations between parasitism and categorical factors were compared using chi-square tests for independence. The point prevalence for both human and dog parasites were calculated for all data as the number of infected individuals divided by the number of individuals sampled $\times 100$. Categorical data were analyzed first with the Chi-square $\left(\chi^{2}\right)$ test for independence as a screening process. This test was followed by stepwise multivariate logistic regression, to account for confounding variables and interactions. For analysis of continuous data (faecal egg count), t-test for independent samples was used to compare means of two groups whereas ANOVA was used to compare means of three or more groups. A $\mathrm{P}$ value $<0.05$ was required for significance. Odds ratios $(\mathrm{OR})$ were determined from the coefficients in the logistic regression.

\section{Results}

\section{Socio-demographic Characteristics}

A total of 384 households were interviewed in Hosanna town. Among these 185 (48\%) were females and 199 (52\%) were males with age of 14 to 83 years old. The average age of the interviewee was 25 years. Out of 384 respondents only $87(22.6 \%)$ of the respondents have some awareness on transmissible helminths between human and dog; their source of information were family or friends $29(7.5 \%)$, veterinarian 18 (4.6\%), television media 15 (3.9\%), other health department $11(2.8 \%)$, Magazines 7 (1.8\%), medical doctors 4 $(1.04 \%)$ and radios $3(0.8 \%)$. Among 384 owners interviewed, 261 owners were able to provide or collect stool/faecal sample (from owners and dogs) for further investigation and the results with different risk factors are presented under (Table $2 \& 4$ ).

\subsection{Gastrointestinal Helminth Parasites in Dogs}

\subsubsection{Overall Prevalence of Helminth Infection and Species of Parasites Identified in Dogs}

Based on coproscopy examination, out of the 261dogs' faecal sample examined, the overall prevalence of intestinal helminth parasites eggs was $71.6 \%(n=187)$.

During the study period the following species of helminth parasites were identified, with their decreasing order of abundance in the household dogs of Hosanna: A. caninum followed by $T$. canis, T. leonina, Taenia species, $S$. stercoralis and $T$. vulpis with a statistically significant variation $\left(\chi^{2}=\right.$ $365, \mathrm{df}=5, \mathrm{p}=0.00)$ and all of them known to have zoonotic important (Table 1).

Table 1. Species of helminth parasites identified in household dogs $(n=261)$ and their prevalence in Hosanna town, south Ethiopia.

\begin{tabular}{llll}
\hline Species of Parasite identified & No Positives & Prevalence (\%) & 95\%CI \\
\hline Ancylostoma species & 124 & 49 & $41.3-53.7$ \\
Toxocara canis & 89 & 34 & $\mathbf{p}-\mathbf{v a l u e}$ \\
Strongyloides stercoralis & 7 & 2.6 & $1.1-5.4$ \\
Toxocara leonine & 19 & 7.2 & $4.4-11.1$ \\
Trichuris vulpis & 5 & 1.9 & $0.6-4.4$ \\
Taenia species & 11 & 4.2 & $2.1-7.4$ \\
Overall & 187 & 71.65 & $65.75-77.03$ \\
\hline
\end{tabular}




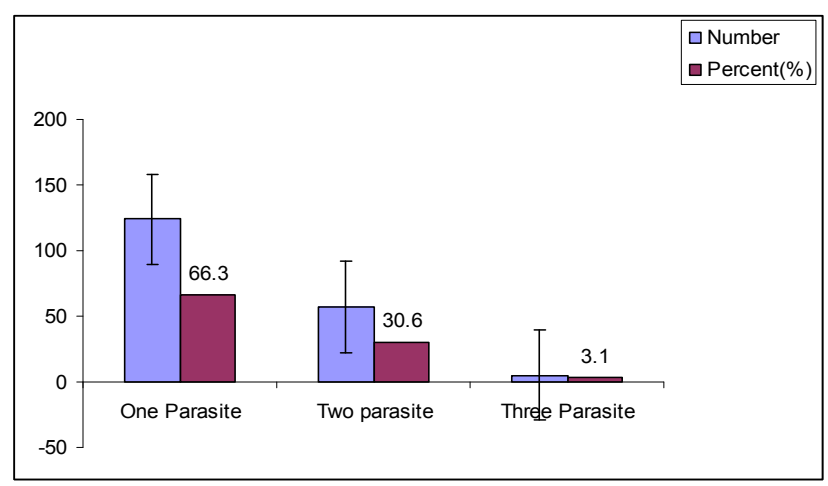

Figure 2. The number (with SD error) and percentage of dogs infected with one, two and three helminth species among the 187-helminth infection positive animals.

Among the 187 dogs positive for helminth infection, $66.3 \%, 30.6 \%$ and $3.1 \%$ of them were infected with one, two and three helminth species respectively (Figure 2). All of the five animals infected with three species of helmenth were found to harbor: T. canis, A. caninum and T. vulpis. Among the 58 dogs found to be infected with two species: forty-five, nine and three of them were infected with $T$. canis and $A$. caninum, Strongloides species and T. canis, and T. leonina and $T$. canis at the same time, respectively.

Gastrointestinal helminth parasitic prevalence in different kebeles of Hosanna.

The overall prevalence of gastrointestinal helminth parasite in the different kebeles of Hossana town is depicted in (Figure 3). Relatively a high prevalence was recorded from faecal samples collected from Arada and Meni-Amba kebeles (Meli-Amba).

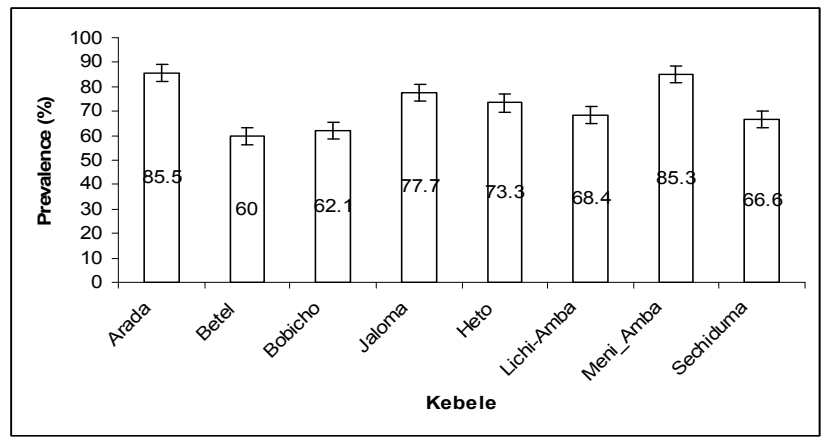

Figure 3. The overall prevalence of gastrointestinal helminth infection in dogs living in different kebeles of Hosanna town, south Ethiopia.

\section{EPG result or density.}

The overall density or mean EPG counts $(E P G \pm$ Std. Err) for A. caninum, T. canis, S. stercoralis and T. leonina were $734 \pm 497.9,1452.8 \pm 1087.5,700 \pm 325$ and $842.8 \pm 271.6$. Upon one-way analysis of variance (ANOVA) a statistical significant variation was observed among the mean faecal egg count each parasite species identified in this study $(\mathrm{F}=$ $12.87, \mathrm{P}=0.000)$ (Figure4).

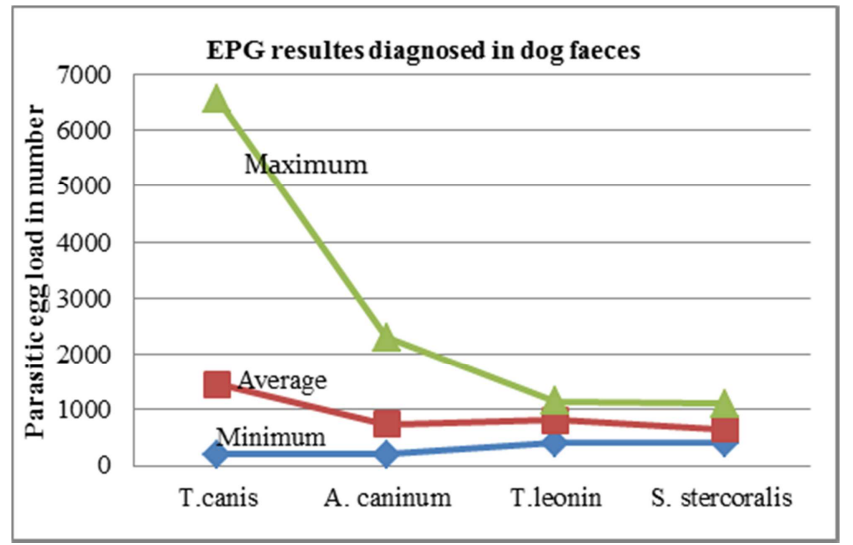

Figure 4. The minimum and maximum helminth parasitic egg loads in different species in infected dogs in Hosanna town, south Ethiopia.

\subsubsection{Assessment of the Effect of the Different Risk Factors Considered for the Helminth Parasitism in Dogs}

Simple bivariate and multivariate analysis was used to determine which risk factors were associated with the risk for infection with intestinal helminth parasites in dogs. The results are presented as chi-square with their p-value and odd ratios with $95 \%$ confidence interval.

Age of dogs and prevalence of gastrointestinal helminth parasites

In this study, the dogs were classified in to three age groups, less than one, between one and three and greater than three years. As it is presented in Table 2 the prevalence was found to be high $(80 \%)$ in very young dogs $(<1$ year) with no statistical significance variation. Its OR (1.94) estimate that gastrointestinal parasitism was approximately 2 times more likely to occur among dogs less than one year than those dogs between one and three and greater than three years.

Practice of de-worming of dogs and gastro intestinal helminth parasitism.

Table 2 describes that dogs which are kept in households who don't practices deworming of their pets were 16 time more infected than households who were deworming their $\operatorname{dogs}(\mathrm{OR}=16,95 \% \mathrm{CI}=7.1-35, \mathrm{P}=0.000)$.

Shelter type used for dogs and parasitism.

In this study infection with intestinal helminth parasites was observed to be more common $(\mathrm{OR}=3.3,95 \% \mathrm{CI}=1.5$ 7.5) among dogs which share house with the owners than those dogs which are kept in open air, kennel and with livestock and significance variations were observed ( $\mathrm{p}$ value $=0.022$ ) (Table 2).

Awareness status on zoonotic helminth transmission and dog parasitism.

The result of simple bivariate analysis showed a high risk of helminth infection in dogs which kept by owners who have got no awareness of disease transmission from dog to human than dogs resided in households who have awareness $(\mathrm{OR}=2.5,95 \% \mathrm{CI}=1.36-4.40, \mathrm{P}=0.002)$ 
Table 2. Prevalence and different risk factors of zoonotic intestinal helminthes parasites in dogs in Hosanna town, South Ethiopia.

\begin{tabular}{|c|c|c|c|c|c|}
\hline Variables or risk factors & Categorical parameters & Total sampled N (\%) & Prevalence N (\%) & OR(95\%CI) & $X^{2}$ (p-value) \\
\hline \multirow{3}{*}{ Age of dog } & $<1 \mathrm{Yr}$ & $82(31.4 \%)$ & $66(80.4 \%)$ & $1.94(0.9-3.8)$ & \multirow{3}{*}{$4.620(0.099)$} \\
\hline & $2-3 \mathrm{Yr}$ & $82(31.4 \%)$ & $55(67 \%)$ & $0.96(.5-1.8)$ & \\
\hline & $>3 \mathrm{Yr}$ & $97(37.2 \%)$ & $66(68 \%)$ & Refer & \\
\hline \multirow{7}{*}{ Kebelles' } & Arada & $28(10.7 \%)$ & $24(85.7 \%)$ & $3(0.8-10.6)$ & \multirow{7}{*}{$11.42(0.112)$} \\
\hline & Betel & $39(14.9 \%)$ & $23(58.9 \%)$ & $0.8(0.2-1.8)$ & \\
\hline & Bobicho & $29(11.1 \%)$ & $18(62.1 \%)$ & $0.82(0.3-2.3)$ & \\
\hline & Heto & $30(11.5 \%)$ & $22(73.3 \%)$ & $1.4(0.5-3.9)$ & \\
\hline & Lichi-amba & $38(14.6 \%)$ & $26(68.4 \%)$ & $1.1(0.4-2.8)$ & \\
\hline & Meli-amba & $34(13.0 \%)$ & $29(85.2 \%)$ & $2.9(0.9-9.4)$ & \\
\hline & Sechiduna & $36(13.8 \%)$ & $24(66.6 \%)$ & Refer & \\
\hline \multirow{2}{*}{ No of dogs owned per Hh } & one dog & $183(70.1 \%)$ & $127(69.3 \%)$ & Refer & \multirow{2}{*}{$1.524(0.217)$} \\
\hline & $>2$ & $78(29.9 \%)$ & $60(77 \%)$ & $1.5(0.8-2.7)$ & \\
\hline \multirow{3}{*}{ Housing practice of dog } & Kennel & $107(41.0 \%)$ & $70(65.4 \%)$ & Refer & \multirow{3}{*}{$9.659(0.022)$} \\
\hline & Mixed with livestock & $33(12.6 \%)$ & $23(69.6 \%)$ & $1.22(0.5-2.8)$ & \\
\hline & Share with family & $66(25.3 \%)$ & $57(86.3 \%)$ & $3.3(1.5-7.5)$ & \\
\hline \multirow{2}{*}{ Treatment for dog } & No & $219(83.9 \%)$ & $178(81.2 \%)$ & $16(7.1-35)$ & \multirow{2}{*}{$62.14(0.000)$} \\
\hline & Yes & $42(16.1 \%)$ & $9(21.4 \%)$ & Refer & \\
\hline \multirow{2}{*}{ Awareness on ZIHP } & No & $196(75.1 \%)$ & $150(76.5 \%)$ & $2.5(1.36-4.4)$ & \multirow{3}{*}{$9.238(0.002)$} \\
\hline & Yes & $65(24.9 \%)$ & $37(56.9 \%)$ & Refer & \\
\hline Valid & & $261(100 \%)$ & $187(71.5 \%)$ & & \\
\hline
\end{tabular}

\subsection{Gastrointestinal Helminth Parasites in Human}

\subsubsection{Overall Prevalence of Helminth Infection and Species of Parasites Identified in Human}

Analysis of the 261 stool sample of subjects revealed an overall prevalence of $17.62 \%(95 \% \mathrm{CI}=13.20-22.79)$. Hookworm species (6.5\%) followed by Ascaris lumbercoids (4.6\%), Hymenolepis nana (2.7\%), Strongyloide stercoralis (1.5\%), Taenia species $(1.5 \%)$ and Hymenolepis diminatus $(0.8 \%)$ were found the most frequently observed helminth parasite species in households of Hosanna town and listed under (Table 3).

Table 3. Species of Helminth parasites identified in dogs owners $(n=261)$ and their prevalence in Hosanna town, south Ethiopia.

\begin{tabular}{llll}
\hline Species of Parasite identified & No Positives & Prevalence (\%) & 95\%CI \\
\hline A. lumbercoids & 12 & 4.6 & $2.06-7.14$ \\
Hook worm spp. & 17 & 6.5 & $3.51-9.49$ \\
Hymenolepis nana & 7 & 2.7 & $0.73-4.67$ \\
Strongyloide stercoralis & 4 & 1.5 & $0.03-2.97$ \\
Taenia spps & 4 & 1.5 & $0.03-2.97$ \\
Hymenolepis diminatus & 2 & 0.8 & - \\
Over all & 46 & 17.6 & $13.20-22.79$ \\
\hline
\end{tabular}

Kebele wise distribution of gastrointestinal helminth parasitic prevalence in children.

The overall prevalence gastrointestinal helminth parasites in the different Kebele's of Hossana town are described. Relatively a high prevalence was recorded from feacal samples collected from Bobicho(27.58\%) and Heto(26.60\%) kebeles', however no statistical variation was observed among the eight kebeles $\left(\chi^{2}=9.87, \mathrm{df}=7, \mathrm{P}=0.196\right)$.

\subsubsection{Assessment of the Effect of the Different Risk Factors Considered for the Helminth Parasitism in Human}

Analysis was used similarly; risks in dog above, determining which risk factors were associated with the risk for infection with intestinal helminth parasites in human. The results are presented using chi-square with their $p$-value and odd ratios with $95 \%$ confidence interval.

Sex of children and helminth parasitism

The risk of intestinal parasitism occurrence among those females was found approximately 1.3 times more likely than those males as described in (Table 4)

Occupation and parasitism

Analysis result in (Table 4) show that the $(\mathrm{OR}=4.3$, $95 \% \mathrm{CI}=1.7$ to 11.1 ) estimates that intestinal parasitism is four times as likely to occur among farmers(soil occupation) than those among other occupation(daily laborer, private business and employers) with a significance association ( $p$ value $<0.005$ )

Disposal ways of dog faeces with helminth parasitism

Out of the study populations parasitism were associated among those who use dog faeces for agricultural composting and found about 2.83 times more likely to occur than those 
have practiced to buried, waste bin and those who do not applicable of dog faeces with a confidence interval of 1.01 to 8.3. This confidence interval suggest that intestinal parasitism among those composting of dogs faces in the study population could be as little as 1.01 times or much as 8.3 times likely to be occur than those other disposal practice of dog faeces with a $\mathrm{p}$ value $<0.05$ (Table 4 ).

Defecation area of dog and intestinal parasitism
In this study infection with intestinal helminth parasites was observed to be more common $(\mathrm{OR}=2.9,95 \% \mathrm{CI}=1.1$ 8.1) among those human population that their dogs defecate inside home or yard than those outside of their home or yard and both in and out defecation of dog (Table 4).

In a summarized form table 4 also presented here under with different risk factors considered for helminth parasitism

Table 4. Result of logistic regression analysis for factors potentially associated with zoonotic intestinal helminth parasites among dog owners in Hosanna town, south Ethiopia.

\begin{tabular}{|c|c|c|c|c|c|}
\hline Variables or risk factors & Categorical parameters & Total sampled N (\%) & Prevalence N (\%) & OR(95\% CI) & $X^{2}$ (p-value) \\
\hline \multirow{2}{*}{ sex of children } & Female & $84(32.2 \%)$ & $17(20.2 \%)$ & $1.3(0.6-2.5)$ & \multirow{2}{*}{$.583(0.445)$} \\
\hline & Male & $177(67.8 \%)$ & $29(5.1 \%)$ & Refer & \\
\hline \multirow{4}{*}{ Educational Status } & Illiterate & $16(6.1 \%)$ & 0 & $.000(00)$ & \multirow{4}{*}{$13.03(0.005)$} \\
\hline & Primary & $93(35.6 \%)$ & $26(28 \%)$ & $3.5(1.3-9.1)$ & \\
\hline & Secondary & $92(35.2 \%)$ & $14(15.2 \%)$ & $1.61(.58-4.4)$ & \\
\hline & College \& above & $60(23.0 \%)$ & $6(10 \%)$ & Refer & \\
\hline \multirow{4}{*}{ Occupation } & Farmer & $49(18.8 \%)$ & $17(34.7 \%)$ & $4.3(1.7-11.1)$ & \multirow{4}{*}{$15.01(0.005)$} \\
\hline & Private business & $69(26.4 \%)$ & $7(10.1 \%)$ & $0.91(.31-2.6)$ & \\
\hline & Student & $34(13.0 \%)$ & $7(20.6 \%)$ & $2.1(.69-6.4)$ & \\
\hline & Employer & $73(28.0 \%)$ & $8(10.9 \%)$ & Refer & \\
\hline \multirow{2}{*}{ No of people in house hold } & $<3$ people/hh & $148(56.7 \%)$ & $22(14.8 \%)$ & Refer & \multirow{2}{*}{$1.79(0.181)$} \\
\hline & $>4$ people/hh & $113(43.3 \%)$ & $24(21.2 \%)$ & $1.54(.81-2.9)$ & \\
\hline \multirow{2}{*}{ Breed of dog } & Local & $207(79.3 \%)$ & $33(15.9 \%)$ & Refer & \multirow{2}{*}{$1.95(0.163)$} \\
\hline & Exotic & $54(20.7 \%)$ & $13(24 \%)$ & $1.7(0.8-3.4)$ & \\
\hline \multirow[t]{2}{*}{ Purpose or use of dog } & Hobby & $25(9.6 \%)$ & $7(28 \%)$ & $2.02(0.55-7.4)$ & \multirow[t]{2}{*}{$2.06(0.358)$} \\
\hline & Both & $31(11.9 \%)$ & $5(16.1 \%)$ & Refer & \\
\hline \multirow{3}{*}{ Defecation area of dog } & Inside my home/yard & $106(40.6 \%)$ & $24(22.6 \%)$ & $2.9(1.1-8.1)$ & \multirow{3}{*}{$3.83(0.148)$} \\
\hline & Outside my home/yard & $99(37.9 \%)$ & $16(16.2 \%)$ & $2.0(0.7-5.9)$ & \\
\hline & Both in \& out side my home/yard & $56(21.5 \%)$ & $6(10.7 \%)$ & Refer & \\
\hline \multirow{4}{*}{$\begin{array}{l}\text { Disposal ways of dog } \\
\text { feaces }\end{array}$} & Buried & $39(14.9 \%)$ & $4(10.25 \%)$ & Refer & \multirow{5}{*}{$10.7(0.013)$} \\
\hline & Not applicable & $120(46.0 \%)$ & $16(13.3 \%)$ & $1.83(.7-4.8)$ & \\
\hline & West bin & $68(26.1 \%)$ & $14(20.6)$ & $2.7(1.1-7.2)$ & \\
\hline & Composting & $34(13.0 \%)$ & $12(35.3 \%)$ & $2.83(1.01-8.3)$ & \\
\hline Valid & & $261(100 \%)$ & $46(17.6 \%)$ & & \\
\hline
\end{tabular}

\subsection{Detection of the Eggs of Helminth Parasites from Soil Samples}

The sample size determination procedure followed in collecting soil sample to detect helminths eggs from dog had its own limitations. Out of the seven purposively collected soil samples, upon laboratory analysis helminth eggs were found in five of the soil samples. The species and number of eggs found from the collected soil samples revealed the occurrence of environmental contamination and risk of infection to human. Table 5 shows the type of eggs recovered and site of soil samples collected and examined, the overall prevalence of intestinal helminth parasites eggs were $71.4 \%(n=5)$. The most frequent species were Trichuris species (57.1\%), Toxocara species (57.1\%), Ancylostoma species (42.8\%), A. lumbricoids (42.8\%), Strongyloides species (14.3\%) and Taenia species (14.3\%). Three species were detected from: market area, CPG1 (children play ground Meli-amba), CPG3 (children play ground Areda) and $\mathrm{G} / \mathrm{M}$ (minor market area around gofermeda) and four species were identified from abattoir area but non-from CPG2 (children play ground Sechiduna) and MA (maremia area) plots.

Table 5. Important geo-helminth parasites egg diagnosed in soil sample of seven selected sites or plots and their prevalence in Hosana town, south Ethiopia.

\begin{tabular}{|c|c|c|c|c|c|c|c|c|}
\hline \multirow{2}{*}{ Geo-helminths Species } & \multicolumn{7}{|c|}{ Plots or sites } & \multirow{2}{*}{ Total N (\%) } \\
\hline & Abattoir & Market & CPG 1 & CPG 2 & CPG 3 & G/M & MA & \\
\hline Ancylostoma spp & 1 & 1 & 0 & \multirow{6}{*}{$\begin{array}{l}\text { No clear } \\
\text { parasitic } \\
\text { contents } \\
\text { were } \\
\text { observed }\end{array}$} & 1 & 0 & \multirow{6}{*}{$\begin{array}{l}\text { No clear } \\
\text { parasitic } \\
\text { contents were } \\
\text { observed }\end{array}$} & $3(42.8 \%)$ \\
\hline A. lumbercoids & 0 & 1 & 1 & & 0 & 1 & & $3(42.8 \%)$ \\
\hline Strongyloides spp & 0 & 1 & 0 & & 0 & 0 & & $1(14.3 \%)$ \\
\hline Taeni spp & 1 & 0 & 0 & & 0 & 0 & & $1(14.3 \%)$ \\
\hline Toxocara $\mathrm{spp}$ & 1 & 0 & 1 & & 1 & 1 & & $4(57.1 \%)$ \\
\hline Trichuris spp & 1 & 0 & 1 & & 1 & 1 & & $4(57.1 \%)$ \\
\hline
\end{tabular}

CPG $1=$ children play ground Meli-amba, CPG $2=$ children play ground Sechiduna, $\mathrm{CPG} 3=$ children play ground Areda, G/M = mini market area around Gofermeda, MA = Maremia area. 
The summary of Helminth parasites identified from samples of human, dog and soil are presented in (Table 6).

Table 6. Overall summary of intestinal helminthes species identified in dogs, human and soil with their prevalence in Hosanna town, south Ethiopia.

\begin{tabular}{|c|c|c|c|}
\hline Species of Parasite identified & Prevalence in Dog N (\%) & Prevalence in human $\mathrm{N}(\%)$ & Prevalence in Soil N (\%) \\
\hline Ancylostoma spp & $124(49 \%) * *$ & $17(6.5 \%)^{*}$ & $3(42.8 \%) * *$ \\
\hline A. lumbercoids & - & $12(4.6 \%)$ & $3(42.8 \%)$ \\
\hline Toxocara spp & $89(34 \%){ }^{\Delta \Lambda} \& 19(7.2 \%)^{\mathbf{\Delta}}$ & - & $4(57.1 \%)^{\wedge \Lambda}$ \\
\hline S. stercoralis & $7(2.6 \%)$ & $4(1.5 \%)$ & $1(14.3 \%)$ \\
\hline Trichuris spp & $5(1.9 \%)$ & - & $4(57.1 \%)$ \\
\hline Hymenolepis nana & - & $2(0.8 \%)$ & - \\
\hline H. diminatus & - & $7(2.7 \%)$ & - \\
\hline Taenia spp & $11(4.2 \%)$ & $4(1.5 \%)$ & $1(14.3 \%)$ \\
\hline Overall parasitism & $187(71.6 \%)$ & $46(17.6 \%)$ & $5(71.4 \%)$ \\
\hline
\end{tabular}

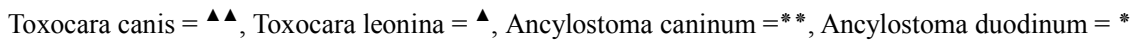

\section{Discussions}

Helminths infection is one of the most neglected tropical diseases (NTDs). Thus, it is considered as no or little attention is given from the donor community and public health planners to mitigate helminthiasis [31]. According to the present study in dogs, dog owners and soil analysis in Hosanna town the results revealed that intestinal helminth species were abundant, and that prevalence and density of infection was very high. The knowledge, attitude and practice of dog owners regarding zoonotic helminthes parasites transmitted by dogs were insufficient.

Although similar findings have been previously documented in dogs throughout the world [32-33], the prevalence and the parasitic load have been reported to differ from region to region depending on many reasons. Results of the current study showed that all helminth parasites species of nematode (T. canis T. leonina, T. vulpis, S. stercoralis and A. caninum) and cestode (eggs of Taeniids spp) detected in the faecal samples of studied dogs are recognized as having a potential public health hazard.

The overall helminth parasite prevalence (71.6\%) in dog recorded in the present study is higher than previous similar coprological studies who reported prevalence's of 51 and $52.9 \%[14,17]$ and is less than from previous $90.7 \%$ and $86.8 \%$ documented in this country $[18,34]$ respectively. The achieved prevalence is also higher than the $52.4 \%$ found by [35] in Argentina, and 53\% in Hungary [36]. Present study result agrees with the $68.4 \%$ recorded by [37] in Nigeria and $76 \%$ in Philadelphia [38]. In contrast, similar study done in some developed countries revealed a very low prevalence's of gastrointestinal parasites when compared to the present finding, for example $4.2 \%$ in Netherlands by [39], 20.4\% in Belgium by [40], 25\% in UK by [41]. This difference can be associated with a high-level awareness about dog parasites and socioeconomic status of dog owners in developed countries for hygiene and make use of the available veterinary cares for their animals [15]. In addition to this some factors such as geographic location and diagnostic technique employed, demographic factor and anthelminthic usage are also responsible for the wide variety of endoparasite prevalence $[11,42]$.
Infection with only one species of parasite was more common $(60.3 \%)$ than infection with mixed species. Similar observations have been documented in different places of this country in Debre Zeit 76.5\% [17] and in Wondo Gent 73.6\% [18]. In contrast infection with mixed helminth species were reported with similar studies conducted in Jimma town 73.6\% [11], in Ambo town 62.14\% [14] and in Hawassa $81.2 \%$ [34]. This difference may be due to the level of awareness about dog parasite, Geographic location, high temperature and relative humidity, housing and other management activities practiced in these areas creates more suitable for the mixed helminth infection of dog.

The predominant species of zoonotic helminth parasite observed in this study was A. caninum (49\%), which is in agreement with previous documents here in Ethiopia [11,34] who reported the prevalence of $58.8 \%$ and $49 \%$ respectively and other countries such as Brazil [42, 43], Argentina [35] and in Tanzania [44]. In contrast, the current study prevalence report was higher than previous reports with similar study in this country [17] prevalence of $32 \%$ in Deberzeit and [14] $35.7 \%$ in Ambo area. This is due to different reasons for instance, management factors like the owners allowed their dogs to spent its major time to freely move. Thus, can easily acquired infection 82(74.5\%) were positive out of $110(42.1 \%)$ dogs that were moved freely and housing practice of dog (out of 261 dogs, 66(25.3\%) were share with family and from this $57(86.3 \%$ ) were positive for this helminth infection and lack of awareness of owners on zoonotic intestinal helminth parasites (out of $75.1 \%$ dogs, $76.5 \%$ were infected).

The second most prevalent helminth parasite in this study was $T$. canis $(34 \%)$. Its prevalence was lower than prevalence rate reported in Wondo Gent $(53.9 \%)$ by [18] but higher than prevalence rate in Jimma, Ambo, Deberzeit and Hawassa town reported that $25.8 \%, 17.14 \%, 21 \%$ and $25.1 \%[11,14$, $17,34]$ respectively. In addition, the prevalence rate of Toxocara infection reported here was higher than the previous reports from other developed country Belgium [40]. This might be due to host factor like exotic breeds are more susceptible than local, agent factors like both trancplacental and trancmammary transmission ability of $T$. canis, puppies are usually born with or acquire ascarid infections early in 
life [45]. This occasions further increased by no deworming history (out of $83.9 \%$ of not dewormed dog $81.2 \%$ were positive for the helminth infection) and also associated with loamy clay type of soil of the present study area or suitable environmental factors created a bit of higher prevalence rate of this agent.

The low prevalence of Taenia eggs and the absence of Spirocerca lupi eggs in fecal samples may be due to the floatation medium (sodium chloride whose specific gravities $=1.2$ ) used in the present study. There are other floatation medias with higher specific gravities (such as saturated solutions of magnesium sulphate or zink sulphate or sodium nitrate) which, when used with the fecal floatation method, yield higher numbers of eggs and therefore prove to be more sensitive [46]. The absence of $D$. caninium may be associated with the absence of flea intermediate host, since dogs are infected with only ingesting this intermediate host.

It is surprising to see that all existing kebelles of Hosanna town: Arada, Betel, Bobicho, Jaloma, Heto, Lichi-amba, Meli-amba and Sechiduna were found to show high prevalence of $85.7 \%, 60 \%, 62.1 \%, 77.7 \%, 73.3 \%, 68.4 \%$, $85.3 \%$ and $66.6 \%$ dog parasitism, respectively. This clearly indicated that there is high prevalence of helminth parasitism in all kebelles of the town. This also shows high risk of human infection of parasitism directly by accidental ingestion or indirectly via from egg contaminated environments either by accidental ingestion of egg/larva or per-cutaneous penetration of hookworm or Strongyloides. This high prevalence in dog is probably due to making light/ignorant property of dog owners to their dog parasitism, no treatment for dog, no veterinary clinics to perform stool examination, no/poor awareness of dog owners on the zoonotic transmission and spread of helminthes parasitic infection from dog to human.

In current study the higher parasitic load were estimated in $T$. canis followed by $T$. leonine, A. caninum and S. sterocorali with their mean EPG of feaces $(E P G \pm$ Std. Err) $1452.8 \pm$ 1087.5, 842.8 $\pm 271.6,734- \pm 497.9$ and $700 \pm 325$ respectively. This finding is in line with that of [11] in Jimma, Ethiopia but higher than the finding of [10] in Nigeria. This might be due to lack of any treatment/deworming of dog and control intervention in the study area.

In the present study based on stool examination of dog owner's children, the results showed that overall prevalence of intestinal helminth parasites was $17.6 \%$ and these comprised egg of Hook worm spps (6.5\%), Ascaris spp (4.6\%), H. nana (2.7\%), Strongyloid spp (1.5\%), Taenia spps $(1.5 \%)$ and $H$. diminatus $(0.8 \%)$. This is from apparently healthy peoples without any clinical history and symptoms of intestinal helminthiasis.

In this study, based on cross sectional stool examination the overall prevalence of intestinal helminth infection $(17.6 \%)$ and this prevalence was lower when compared with similar previous study in children around Lake Ziway Island with an overall prevalence of $56.7 \%$ [47]. This result is also lower compared to that reported in South Wello (43.3\%) [48], in Southern and Central Zones of Tigray (56.4\%) by [49] and $(82.4 \%)$ by [24] in Zarima town, Northwest Ethiopia. The lower prevalence obtained in the present study may be due to availability of latrine (to avoid re-infection) and health centers (for frequent stool check up/examination), exclusion were not performed those who had take antihelminthics during specimen collection from study subjects (since, antihelminthic reduces the probability of positive results) and also the technique used in stool examination in the present studies less sensitive than the previous studies.

Over all kebelles wise distribution of helminth parasitism in human from the town: Arada, Betel, Bobicho, Jaloma, Heto, Lichi-amba, Meli-amba and Sechiduna were 7.10\%, $15.40 \%, 27.58 \%, 22.20 \%, 26.60 \%, 21.05 \%, 5.88 \%$ and $16.66 \%$ respectively. The prevalence from Bobicho, Heto and Lichi-amba was a bit higher when compared with other kebelles though statically not significant variations among kebelles. This might be due to the their occupation (farmers are four times more infected than those other occupation), they use dog faeces as a composting ways of disposal, they are town border kebelles and relatively no health center access like that of relatively lower prevalent kebelles.

A dog tapeworm Hydatidosis /Cystic echinococcosis is a major endemic disease of public health important in various parts of this country [50] mainly in Southern Ethiopia. According to some studies the prevalence of this parasite was reported as $61.5 \%$ by postmortem examination in Wondo Gent [18]. Thus, E. granulosus, a major zoonotic parasite of livestock and dogs in Ethiopia, these is probably due to the close association between dogs, livestock and humans [50]. The fact that dogs enjoy unrestrained with humans, scavenge for food in an environment contaminated with faecal material of potential intermediate hosts and feed on offal of slaughtered livestock in abattoirs, makes transmission of zoonotic parasitic diseases predictable in the studied area.

Based on soil sample investigation of present study, the results revealed that a $71.4 \%$ geohelminth parasites eggs content from the study environment and this comprised eggs of Ascaris (42.8\%), Ancylostoma species (42.8\%), Trichuris species (57.1\%), Toxocara species (57.1\%), Strongyloides species $(14.3 \%)$ and Taenia species (14.3\%). Due to the fact that the adult stages of these worms reside in the intestine, the presence of the eggs in soil is indicative of faecal pollution. This is proved by the fact that around abattoir, market area and some selected different children play ground, which had the highest prevalence of geohelminths [9]. This is due to in these environments there is no toilet facilities even for human beings and surrounded by bush which create favorable condition to excrete/defecate their stool/faeces. This open defecation, uncontrolled dog movement or management, high close relationship with dogs and lack of awareness on environmental contamination from dog faces results in the eggs being washed and disseminated with rain, wind and insects then the area being highly contaminated with eggs of the parasites and high risk of re infection [29].

There are no similar studies to evaluate the degree of soil contamination in Ethiopia when comparing the data published 
until now. Comparing the result of soil sample analysis with other finding obtained elsewhere seems very difficult due to the small sample size we considered. However, the helminth eggs found in the soil samples were known in causing cutaneous larva migrants in human specially children [51]. The degree of helminth parasitic egg contaminated environment in the present study was $71.3 \%$, which is similar to the $66 \%$ in London [38], and the $77 \%$ found in Montreal [52]. The achieved prevalence is also higher than the $40 \%$ [53] in Philadelphia and $18 \%$ in Spain [29]. These is due to the expansion of high uncounted number of stray dogs from rural surrounding areas of the country and high ownership of dogs with suitable climatic factors required for the biology of the parasites, inadequate veterinary facilities and no/ very few public awareness to take care of the dogs.

Although the comparison of surveys is difficult due to the differences in sampling, diagnostic techniques used, weather, geographical areas, results of current study indicate that the main risk to public health in detection of eggs of helminth parasites form soil samples is Toxocara species (57.1\%), the etiological agent of visceral and ocular larva migrans in human. Similar results were found in public area $50 \%$ in Italy [12]. This egg contamination suggests a real risk of human infection, especially to small children who share playgrounds with pets. Toxocara eggs need an incubation period of (2- 6 weeks) before its eggs become infective and this also prolongs further risk of zoonotic transmission in environment [54].

In general, the present study demonstrated that the prevalence of the helminth infection $71.6 \%, 17.6 \%$ and $71.4 \%$ were in dogs, human and soil respectively, based on coprological or parasitological techniques. This prevalence's were influenced by different risk factors of KAPs (knowledge, attitude and practices) of dog owners. For instance, treatment for dogs, awareness of dog owners on transmissible $\mathrm{ZIH}$ (zoonotic intestinal helminthes) and housing practice for dog were associated to the occurrence of intestinal helminthasis in dog with a statically significant variation value of $62.142(0.000), 9.238(0.002)$ and $9.659(0.022)$ respectively. This might be due to lack of access to veterinary services and poor or no awareness of dog owners on zoonotic intestinal helminthes. Then the ova of intestinal helminthes species are passed in the faeces of their host; thus, environmental egg contamination proportions of the present study were $71.4 \%$ recorded and it is obvious on public health impact. The main route by which human beings become infected with zoonotic helminth parasites is both via pica/eating soil and by contacting/children play with dogs and soil. Small children are considered particularly at risk due to their lifestyle, especially if they play on contaminated soils. Soil contamination is the best indicator of the risk of zoonotic transmission $[54,55]$. So, by possible care of dog, environmental egg contamination must be controlled to prevent zoonotic transmission.

Out of 384 respondents' only $87(22.6 \%)$, respondents' have some awareness on transmissible helminthes between human and dog from different responsible organs like from Veterinarian 18 (4.6\%), Medical doctors 4(1.04\%), other health department $11(2.8 \%)$, television media $15(3.9 \%)$, radios 3(0.8\%), Magazines $7(1.8 \%)$ and family or friends 29 (7.5\%). Though, the awareness/information source not accessible, similar awareness $(22 \%)$ were recorded here in Ethiopia, in Wendo Gent [18]. In contrast high level of awareness was recorded in Perth, Australia [56]. These differences might be associated with veterinary facilities, socio economy, professional manpower and availability of adequate information in different mass Medias in developed nations.

In the present study, it is surprising to see that the transmissibility in human-dog-environment interface was detected. For instance, Strongyloides stercoralis were identified or diagnosed in both dogs and dog owners from the same households with similar KAPs of dog owners. During cross sectional KAPs survey of dog owners in the Hosanna town, seven owners responded that similar responses and then according to coproscopy analysis the result revealed that all 7(2.6\%) owners' dogs were harbor a single $4(1.5 \%)$ strongyloides and double infection $3(1.15 \%)$ with strongyloides and toxocara canis. In contrast 3(1.15\%) human beings were infected with this helminth species from out of $4(1.5 \%)$ human strongyloides infection identified from 261 stool human sample. This might be due to sharing the same house, children played with dogs, poor management practice and level of awareness of dog owners about dog parasites and associated risk, in addition to lack of veterinary attention, could exacerbate risk of transmission of canine parasitic zoonoses to human community [14].

\section{Conclusion and Recommendations}

The present study provides the first systematic assessment and qualitative analysis of parasites, and the prevalent zoonotic gasterointestinal helminthes were estimated in dogs, children's of dog owners and soil of selected environments in Hosanna town, Southern Ethiopia. Cross sectional study revealed the following intestinal helminthes species that includes roundworm (Toxocara \& Ascaris spp), hookworms (Ancylostoma species), hydatid tapeworm (Echinococcus granulosus), whipworm (Trichuris species) and threadworm (Strongyloides stercoralis). The knowledge, attitude and practice of dog owners regarding zoonotic helminthes parasites transmitted by dogs were insufficient. Potential risk factors associated with GI helminthes zoonosis from dogs include: parasite factors, host factors and environmental factors were assessed through structured questioner. Control practices in pet zoonoses like preventive anthelmintic treatment, educating and counseling pet owners in preventing zoonotic diseases and community education, these all were addressed. Based on the above conclusions, the following recommendations are forwarded:

I. Research information on zoonoses from pets in general and zoonotic helminthes from dogs in particular are scarce at national level. Therefore, disease investigation and research in the area of zoonoses from dogs should get special attention all over the country. 
II. Communication and collaboration among human and animal professions should be encouraged for effective disease surveillance system, control and prevention of zoonotic helminthes from dogs.

III. Community awareness in the area of the following points should be undertaken using public forum or media like community radio.

a) Practicing good personal hygiene, particularly washing hands after handling pets and before eating food should be advised;

b) Controlling dog parasite infections through repeated treatments and/or regular diagnostic testing, thus are preventing them from shedding eggs into and contaminating the environment;

c) Avoiding dog to free movement and being contact with wild and domestic animals, and proper management of feeding not allow carcass of a dead animal and condemned offal's feeding;

d) Grooming dogs regularly to minimize the risk of coat contamination with worm eggs;

e) Minimize environmental contamination with infective parasite stages by: avoiding disposal of the faeces or in recyclable waste and with regularly cleaning up of dog faece;

f) Keeping children away from areas that may be contaminated with dog faeces and potential health hazard association to humans, especially in children whose play habits and attraction to dogs put them at increased risk.

\section{Ethical Consideration}

The purpose of this study was explained to the intended study human population and verbal consent were obtained from them before stool sample collection.

\section{Competing Interests}

The author(s) declare that they have no competing interests.

\section{Authors' Contributions}

A. Y. M. directed the study, analysed the data and wrote the manuscript. D. W. G., D. M. A., W. B. A., G. D. G., U. F. L., A. G. G. and G. G. K contributed to the data collection, study methodology and co-wrote the manuscript. A. H. D., H. A. D and G. M. Y. contributed to literature review, data analyses and manuscript editing. All authors read and approved the final manuscript.

\section{Acknowledgements}

We would like to thank the members of the Jimma University College of Agricultural and School of Veterinary Medicine and Hosanna Health Science College for their valuable support, advice and direction on this work. We also recognize the contributions of the local authorities of Hadiya zone Gombora district and Hosanna town administration who commissioned the study and to all those individuals who gave up their time to participate.

\section{References}

[1] Kuma, G. S. and Smith, H., Pets, Poop and Parasites. Microbiology today, (2000). 27: p. 84-86.

[2] Smith, A. and Whitfield, Y., Household Pets and Zoonoses. In Canada, National Collaborating Centre for Environmental Health (2012).

[3] Patricia, Y. R. and Bruno, B. C., Hedgehog Zoonoses University of California, Davis, Davis, California, USA. Emerging Infectious Diseases, (2005). 11: p. 1.

[4] Elmore, A. S., Jones, L. J., Conrad, A. P., Patton, S., Lindsay, S. D and Dubey, P. J., Toxoplasma gondii: epidemiology, feline clinical aspects, and prevention, USA.. Trends in Parasitology, (2010).

[5] Ballweber, R. L., Xiao, L., Bowman, D. D., Kahn, G. and Cama, A. V., Giardiasis in dogs and cats: update on epidemiology and public health significance. Trends Parasitology, (2010). 26: p. 180-189.

[6] Won, K. Y., Deanna, K-M, Schantz, P. M. and Jones, J. L., National Seroprevalence and Risk Factors for Zoonotic Toxocara spp. Infection Amercan Jornal of Tropical Mededicen and Hygine, (2008). 79(4): p. 552-557.

[7] Landmann, J. K. and P. Prociv, Experimental human infection with the dog hookworm, Ancylostoma caninum. The Medical Journal of Australia, (2003). 178: p. 69-71.

[8] Traub, R. J., Robertson, I. D., Irwin, P., Mencke, N., and Thompson, R. C., The role of dogs in transmission of gastrointestinal parasites in a remote tea-growing community in northeastern India. American Journal of Tropical Medicine and Hygiene, (2002). 67(5): p. 539-45.

[9] Weese, S. J., Peregrine, S. A., Anderson, C. E. M. and Fulford, B. M., Companion Animal Zoonoses. Parasitic Diseases. Blackwell Publishing Ltd.. (2011).

[10] Ugbomoiko, S. U., Ariz, L. and Heukelbach, J., Parasites of importance for human health in Nigerian dogs: high prevalence and limited knowledge of pet owners, Nigeria. BMC Veterinary Research, (2008): p. 4:49.

[11] Degefu, H., Tefera, A. and Yohannes, M., Zoonotic helminth parasites in faecal samples of household dogs in Jimma Town, Ethiopia. Journal of Public Health and Epidemiology, (2011). 3(4): p. 138-143.

[12] Habluetzel, A., Traldi, G., Ruggieri, S., Attili, A. R., Scuppa, P., Marchetti, R., Menghini, G. and Esposito, F., An estimation of Toxocara canis prevalence in dogs, environmental egg contamination and risk of human infection in the Marche region of Italy. Veterinary Parasitology, (2003). 113: p. 243252.

[13] Malgor, R., Oku, Y., Gallardo, R, and Yarzabal, I., High prevalence of Ancylostoma species infection in dogs associated with endemic focus of human cutaneous larva migrans in Tacuaremba Uruguay. Parasite, (1996). 3: p 131-134. 
[14] Endrias, Z., Yohannes, S. and Berhanu, M., Prevalence of helminth parasites of dogs and owners awareness about zoonotic parasites in Ambo town, Central Ethiopia. Ethiopia Veterinarians Jornal, (2010). 14(2): p. 17-30.

[15] Schantz, P. M., Zoonotic ascarids and hookworms: The role for veterinarians in preventing human disease. Compendium on continuing education for the practicing veterinarian. (2002). 24(1): p. 47-52.

[16] Legesse, Y. B., Preliminary observational study on captive civet cats (Civettictis civetta) in western Ethiopia. DVM thesis in Addis Abebe University, collage of veterinary medicine. (2001).

[17] Yacob, H. T., Ayele, T., Fikru, R. and Basu, A., Gastrointestinal nematodes in dogs from Debre Zeit. Ethiopian veterinary Parasitologe, (2007). 148: p. 144-148.

[18] Jones, O., Kebede, N., Kassa, T., Tilahun, G. and Macias, C., Prevalence of dog gastrointestinal parasites and risk perception of zoonotic infection by dog owners in Wondo Genet, Southern Ethiopia. Journal of Public Health and Epidemiology, (2011). 3(11): p. 550-555.

[19] HTAO, Hosanna town agricultural office annual reports of animal's population found in the town. (2014).

[20] Tile, D., The welfare of working equines and their socio economic dimension in Hosanna, southern Ethiopia. M. Sc thesis, Jimma University (2012).

[21] Macpherson, C. N. L., Meslin, F. X., Wandeler, A. I., Dogs, Zoonoses and Public Health. CAB International, Wallingford, (2000b): p. 382.

[22] Cisneros-Jimenez, B. E. a R.-M., C., Helminthes and Sanitation. Communicating Current Research and Educational Topics and Trends in Applied Microbiology. A. Méndez-Vilas (Ed.), México. (2007).

[23] Thrusfield, M. V. p., Veterinary Epidemiology. 3rd Edn., Blackwell Science, Oxford, London. (2005): p. 234-238.

[24] Alemu, A., Atnafu, A., Addis, Z., Shiferaw, Y., Teklu, T., Mathewos, B., Birhan, W., Gebretsadik, S. and Gelaw, B., Soil transmitted helminths and schistosoma mansoni infections among school children in zarima town, northwest Ethiopia. BMC Infectious Diseases, (2011): p. 11:189.

[25] Soulsby, E. L. J., Helminths, Arthropodes and Protozoa of Domestic Animals. 7th edition. The English Language Book Society and Bailliere Tindall, London. (1982): p. 809.

[26] Urquhart, G. M., Armour, J., Duncan, J. L., Dunn, J. M. and Jennings, J. W., Veterinary Parasitology. $3^{\text {rd }}$ edition. Longman Scientific and Technical, Burnt Mill, Harlow, UK. (1987): p. 238.

[27] Thienpoint, D., Rochette, F. and Vanporijs, O. F. J., Diagnosing Helmnthiasis by Coprological samples. 2nd edition. Janson Research foundation. Beerse, Belgium. (1998).

[28] Taylor, M. H., Coop, R. L. and Wall, K. L., Veterinary Parasitology. 3rd edition. Black well publishing, UK. (2007).

[29] Dado, D., Izquierdo, F., Vera, O., Montoya, A., Mateo, M., Fenoy, S., Galva'n, A. L., Garc1'a, S., Garc1' a, A., Ara'nguez, E., Lo' pez, L., del A'guila, C. and Miro, G., Detection of Zoonotic Intestinal Parasites in Public Parks of Spain. Potential Epidemiological Role of Microsporidia Zoonoses and Public Health, (2011). 59: p. 23-28.
[30] Angulo-Madero, R., guila, C. A., Puente, de la. and Guille'nLlera, J. L., Contaminacio'n de suelos de parques pu' blicos por Toxocara canis. Rev. Iber. Parasitol. Extraordinario. (1987). 165-171.

[31] WHO, Helminth control in school age children: a guide for managers of control programmes - $2^{\text {nd }}$ editions. (2011).

[32] Senlik, B., Cirak, V. Y. and Karabacak, A., Intestinal nematode infections in Turkish military dogs with special reference to Toxocara canis. Journal of Helminthol., (2006). 80: p. 299-303.

[33] Ugochukwu, E. I., and Ejimadu, K. N., Studies on the prevalence of gastrointestinal helminths of dogs in Calabar Nigeria. International Journal of Zoonoses, (1985). 12: p. 214218.

[34] Paulos, D., Addis, M., Fromsa, A. and Mekibib, B., Studies on the prevalence of gastrointestinal helminthes of dogs and owners awareness about zoonotic dog parasites in Hawassa Town, Ethiopia. Journal of Public Health and Epidemiology, (2012). 4(8): p. 205-209.

[35] Maria, F., Fontanarrosa, D. V., Julia, B. and Diego, E., An epidemiological study of gastrointestinal parasites of dogs from Southern Greater Buenos Aires (Argentina): Age, gender, breed, mixed infections, and seasonal and spatial patterns. Veterinary Parasitology, (2006). 136: p. 283-296.

[36] Fok, E., Szatmri, V., Busk, K. and Rozgonyi, F., Prevalence of intestinal parasites in dogs in some urban and rural areas of Hungary. Vet. Quart., (2001). 23: p. 96-98.

[37] Anene, B. M., Nnaji, T. O. and Chime, A. B., Intestinal parasitic infections of dogs in the Nsukka area of the Enugu State, Nigeria. Preventive Veterinery Medicine, (1996). 27: p. 8994.

[38] Snow, K. R., Ball, S. J. and Bewick, J. A., "Prevalence of Toxocara species eggs in the soil of five east London parks.". Veterinary Record, (1987). 120(3): p. 66-67.

[39] Overgaauw, P. A., Prevalence of intestinal nematodes of dogs and cats in The Netherlands. Vet. Quart., (1997). 19: p. 14-17.

[40] Claerebout, E. S., Casaert, A. C., Dalemans, N. D. and Wilde, L., Giardia and other intestinal parasites in different dog populations in Northern Belgium. Veterinary Parasitology, (2009). 161: p. 41-46.

[41] Wolf, A. a. W., I. P., Human Toxocariasis and direct contact with dogs. Veterinary Records, (2003). 151: p. 419-422.

[42] Katagiri, S., and Oliveral-Sequeeria, T. C. G., Prevalence of Dog intestinal parasites and risk Perception of zoonotic infection by dog owners in Sao Paulo state, Brazil. Zoonoses and public health, (2008). 55: p. 406-413.

[43] Oliveira-Sequeira, T. C., Amarante, A. F., Ferrari, T. B. and Nunes, L. C., Prevalence of intestinal parasites in dogs from Sao Paulo State, Brazil. Veterinary Parasitology, (2002). 103: p. 19-27.

[44] Swai, E. S., Kaaya, E. J., Mshanga, D. A. and Mbise, E. W., A Survey on Gastro-Intestinal Parasites of Non-Descript Dogs in and Around Arusha Municipality, Tanzania. International Journal of Animal Veterinary Adv., (2010). 3: p. 63-67.

[45] Burke, T. M. a. R., E. L., Prenatal and lactational transmission of Toxocara canis and Ancylostoma caninum: experimental infection of the bitch before pregnancy. International Journal for Parasitology, (1985). 15: p. 71-75. 
[46] Sloss, M. W., Kemp, R. L., Zajac, A. M., Veterinary Clinical Parasitology, 6th edition, Iowa State University Press, Iowa. (1994).

[47] Tesfa-Michael, T., and Teklemariam, A., Intestinal helminthic infecton in Lake Zway Isands, central Ethiopia. Ethiopian Medical Journal, (1983): p. 21: 149.

[48] Assefa, T., Woldemicael, T. and Dejene, A., Intestinal parasitism among students in three localites in South Wello, Ethiopia. Ethiopian Journal of Health Division, (1998). 12: p. 231-235.

[49] Dejenie, T. and Petros, B., Irrigation Practices and Intestinal Helminth Infections in Southern and Central Zones of Tigray. Ethiopian Journal of Health Division, (2009). 23(1).

[50] Kebede, N., Mitiku, A. and Tilahun, G., Hydatidosis of slaughtered animals in Bahir Dar Abattoir, Northwestern Ethiopia. Tropical Animal Health and Prodroduction, (2009). 4: p. 43.

[51] Caumes, E., It's time to distinguish the sign "creeping eruption" from the syndrome "cutaneous larva migrans". Dermatology, (2006). 213(3): p. 179-181, 1018-8665.
[52] Ghadirian, E., Viens, P., Strykowski, H. and Dubreuil, F., Epidemiology of toxocariasis in the Montreal area. Prevalence of Toxocara and other helminth ova in dogs and soil. Canadian Journal of Public Health, (1976). 67(6): p. 495-498.

[53] Dubin, S., Segall, S. and Martindale, J., Contamination of soil in two city parks with canine nematode ova including toxocara canis; a preliminary study American Journal of Public Health, (1975). 65(11): p. 1242-1245.

[54] Mazgajska, H., Eggs of Toxocara species in the environment and their public health implications. Journal of Helminthology, (2001). 75: p. 147 - 151.

[55] Barriga, O. O., Rational control of canine toxocariasis by the veterinary practitioner. Journal of American Veterinary Association, (1991). 198: p. 216 - 21.

[56] Bugg, R. J., Robertson, I. D., Elliot, A. D. and Thompson, R. C. A., Gastrointestinal parasites of urban dogs in Perth, Australia. Veterinary Journal, (1999). 157: p. 295-301. 